\title{
La autonomía de lo político frente a lo personal y lo social-económico en la obra de Arendt
}

\section{(The authonomy of politics and its difference with the personal and the social-economic in the work of Arendt)}

\author{
Julia URABAYEN
}

Recibido: 13 de febrero de 2013

Aceptado: 14 de junio de 2013

\section{Resumen}

Este trabajo busca analizar algunos de los problemas implicados en la teoría política de Arendt. Su deseo de establecer una autonomía de lo político le lleva a separar esta actividad de lo personal y de lo social. De este modo excluye del espacio público lo privado y lo económico, lo que supone no atender a aspectos que son fundamentales para entender correctamente la política y el modo en el que se organizan las sociedades actuales.

Palabras claves: Arendt, política, personal, social.

\begin{abstract}
This paper deals with some of the problems involved in the political theory of Arendt. She wants to emphasize the autonomy of politics, such that political activity is different from the personal and social. In this way, the public space excludes the private and the economic. Because of this exclusion, Arendt does not pay attention to certain key aspects of politics; aspects that are necessary in order to understand our present-day societies.
\end{abstract}

Keywords: Arendt, politics, personal, social. 
En este artículo pretendo señalar que la concepción política de Arendt, al intentar evitar el totalitarismo - lo que implica lograr que el racismo no vuelva a convertirse en criterio político- conduce a una exclusión de todo aspecto personal y social del ámbito político. Ante el totalitarismo, la alemana nacionalizada americana propone una noción de política como un espacio de aparición, pluralidad y libertad que pretende liberar a la política de la violencia y establecerla como acción en concierto, iniciativa o capacidad de dar lugar a algo nuevo, lo que siempre requiere la presencia de otros seres humanos ${ }^{1}$. Es decir, ante una comprensión del ser humano que lo encierra en su naturaleza, ella destaca su libertad entendida como iniciativa o natalidad $^{2}$, con la que identifica la política. Con el objetivo de evitar la presencia de lo natural en lo político, Arendt se enfrenta no solo a la injerencia de lo personal en este ámbito, sino también a la posible conversión de lo social en político, lo que explica su crítica a la Revolución Francesa por conceder un lugar preminente a la cuestión social ${ }^{3}$. De igual modo establece una diferencia entre vida biológica (zoé) y vida humana (bios) con el objetivo de lograr que la naturaleza o la vida biológica no se conviertan en un concepto relevante en la política.

Esta delimitación de lo político que busca salvar grandes escollos, sin embargo, plantea serios problemas. El pensamiento arendtiano tiende a establecer distinciones de carácter más bien rígido -y aunque en algunos casos busca la posterior articulación de las categorías que ha separado, la mayoría de las veces no logra una correcta interrelación ni una adecuada comprensión de la complejidad de las relaciones que hay entre esas supuestas esferas- como, por ejemplo, entre labor, trabajo y acción, entre filosofía y política, entre naturaleza y política, entre poder y violencia ${ }^{4}$.

Dada la amplitud de estos temas, en este texto me limitaré a esbozar la separación arendtiana de la política frente a lo privado y lo social, así como algunos de los problemas que surgen de la distinción tan marcada que establece entre la política y la naturaleza, entre lo construido y lo dado, lo libre y lo necesario. Comenzaré por la exclusión de la naturaleza vista como biología y la relegación de lo privado y de

\footnotetext{
${ }^{1}$ La cuestión más delicada es que esta pluralidad por sí sola no asegura el consenso. Cfr. Delruelle (1993), p. 33. Lo mismo sucede con la natalidad: el milagro del nacimiento no garantiza de ningún modo que quien nace sea capaz de dar cumplimiento a una vida política como la entiende Arendt.

2 Arendt encuentra esta relevancia de la libertad en Agustín de Hipona. Cfr. Collin (1992), pp. 48-49.

3 Cfr. Arendt (1988), capítulo 2: "La cuestión social".

4 "Por ello, de nuevo con McCarthy, podemos decir metafóricamente que cada distinción arendtiana es como un pequeño hogar con su arquitectura propia, pero que, al mismo tiempo, separa cada 'casa' de otras sin que se vislumbren sendas entre ellas que hagan posible la comunicación. Cada actividad -labor, trabajo y acción- emerge en claro contraste respecto a las otras dos. Pero es precisamente esta nítida y tajante distinción la que ha provocado duras críticas a su teoría, por considerarla excesivamente rígida y dogmática. [...] Sin embargo, ese mismo modelo resultará un serio lastre que le impedirá establecer posibles conexiones entre las distintas actividades, formulando una excesiva separación entre ellas. En este sentido, tanto Parekh como Benhabib, coinciden en señalar que Arendt incurre en lo que podríamos denominar un esencialismo fenomenológico", Sánchez Muñoz (2003), pp. 134-135.
} 
lo que está unido a ello, a un espacio no público ni político. Continuaré con un breve análisis de la crítica de Arendt al ascenso de lo social y, por tanto, de lo económico, y a la aparición de la sociedad de masas. Concluiré con el problema de la delimitación de lo político en Arendt y con algunas cuestiones críticas implicadas en esta demarcación que muestran la debilidad de la concepción arendtiana de la política a la hora de comprender nuestras sociedades.

\section{La exclusión de lo privado y de lo personal de la política}

El pensamiento político de Arendt nace de una experiencia personal dramática: la situación de paria y apátrida que tuvo que vivir como consecuencia de lo que para ella era simplemente algo dado: su "condición" judía. El nazismo expulsó del espacio político y del mundo a quienes eran judíos por el mero hecho de serlo. De este modo convirtió en político un rasgo que para Arendt no lo es, ya que se refiere a lo que uno es y no a lo que uno hace. Así lo biológico (o lo que el nazismo entendía por tal) se ve como el criterio político por excelencia. Éste es, como señala acertadamente Canovan, el referente más claro de la reflexión política de la pensadora alemana, lo que da lugar a una de sus tesis fundamentales: la política no tiene que ver con lo que es dado5. Es más, debe asumir lo dado y no tratar de modificarlo. Arendt incluye en esa dimensión prepolítica y apolítica, al menos, dos aspectos de su identidad: su ser judía y su ser mujer. Pero su atención teórica se dirige únicamente al estudio del judaísmo y no al de la feminidad 6 . Sus obras abordan el judaísmo y la historia judía con un objetivo político y buscan siempre la universalización de la experiencia del pueblo paria por excelencia 7 . Pero en esas investigaciones una de las figuras es la de una mujer: Rahel Varnhagen. A pesar de ello, y de que uno de sus primeros trabajos fue una recensión sobre un libro que trataba el problema de las mujeres, esta no sintió grandes simpatías por los movimientos de

\footnotetext{
5 Para Arendt la diferencia entre condición y naturaleza humana tiene un sentido humanista, así como la diferencia entre mundo y tierra. Cfr. Canovan (1992), p. 104-106. Arendt llama mundo al espacio público, pero también establece que el mundo es propiamente la condición del trabajo, no de la acción. Es decir, usa de dos modos diferentes el mismo término. Así se diluye algo la distinción acción/trabajo, entre otros motivos, porque la acción se desvanecería si el trabajo no la protegiera, no la conservara como parte del mundo.

6 Ring mantiene que estos son los dos elementos que estructuran su pensamiento, pero que existe una gran diferencia entre ellos. Mientras su ser judía concierne al contenido, su ser mujer ha afectado más a la recepción de su obra que a su articulación. Cfr. Ring (1997), p. 2. Sin embargo, más adelante sostiene que comparte la afirmación feminista de que el discurso público está marcado por el género. Cfr. p. 18. De ahí su intento de mostrar que el ser mujer de Hannah Arendt, y no solo su ser judía, nutre algunas de sus reflexiones políticas más importantes.

7 Como destaca Kristeva, su condición judía para ella era más que un dato biológico. Cfr. Kristeva (2001a), p. 104.
} 
emancipación de las mujeres e intentó no convertirse en una mujer excepcional ${ }^{8}$. Es decir, por una parte, no aceptaba que lo personal fuera político ni deseaba apoyar un movimiento que, según ella, podría llevar a perder ciertos privilegios femeninos (su lema seguía siendo Vive la petite différence!) ${ }^{9}$. Por otra, intentaba no caer en lo que ella misma había analizado en profundidad en su estudio de la asimilación judía, el deseo de ser aceptado como una excepción ${ }^{10}$.

La cuestión central en esta relación con la feminidad se articula en torno a la diferencia público/privado ${ }^{11} \mathrm{y}$ este es uno de los aspectos que destacó la recepción feminista de Arendt de 1975 a los últimos años 8012. Lo primero que hay que recordar es que lo privado es una esfera dotada de valor para Arendt: como ámbito de la producción y la necesidad es "inferior", pero también es el lugar que ofrece la calidez del hogar, de lo que otorga un espacio de protección. De ahí la relevancia de tal esfera y la necesidad de garantizar que no sea afectada por nada externo. Esto se hace más agudo si se entiende que la distinción entre privado y público está pensada sobre el trasfondo de Los orígenes del totalitarismo y se ofrece como el baluarte frente a tal fenómeno13. Sin embargo, el problema más relevante que reside en esta separación es que, en primer lugar, presenta la visión griega de lo privado como privación, como espacio apolítico en el que se desarrollan actividades vinculadas a las necesidades biológicas que lidian con el mantenimiento de la vida y que, como tales, están sometidas a los ciclos naturales y a la violencia propia de la naturaleza. En segundo lugar, Arendt no atiende a la pluralidad de actividades que se realizan en este ámbito y a sus diferencias cualitativas. Si bien es cierto que establece una distinción entre privado e íntimo ${ }^{14}$, esta separación sirve más para criticar a la sociedad moderna y su supuesta tendencia a primar la intimidad -los sentimientos- fren-

8 Cfr. Comesaña (2001), p. 128. Esto está unido a su desagrado a aparecer en público. Cfr. Blücher (1996), p. 236.

${ }^{9}$ El 25 de mayo de 1958, por ejemplo, escribe a su marido: "believe me, my darling, women can only live in marriage", Arendt, Blücher (1996), p. 322. A pesar de eso, Arendt estuvo atenta a los temas relacionados con el feminismo. Cfr. Pitkin (1998), p. 153.

10 Arendt rechaza tener que justificarse o legitimarse. Cfr. Arendt, H., Blücher (1996), p. 10.

11 "She did not think of herself as a feminist and she was deeply skeptical of any single-issue political movement, especially one that brought into question the distinction she drew between the private and the public", Young-Bruehl (1996), p. 307.

12 Cfr. Young-Bruehl (1996), p. 308.

13 Cfr. Young-Bruehl (1996), p. 309.

14 "Lo íntimo y lo privado no son lo mismo. La intimidad es el gran descubrimiento que procede de la experiencia de lo social. La intimidad es lo oculto, de lo que no nos avergonzamos, o que en público no significa vergüenza, Por tanto:

A. Privado: metabolismo con la naturaleza, o trabajo, o metabolismo con lo necesario; mejor dicho: sometido a lo coactivo.

B. Público: aparecer, mostrarse en libertad, donde lo privado se convierte en vergonzoso [...]

C. Sociedad: la unión de la referencia recíproca en la necesidad.

D. Intimidad: amor y amistad. 
te a lo público que para revalorizar las diferentes actividades que tienen lugar en este ámbito.

Por ello, otro aspecto que destaca son los "olvidos" que tal falta de cualificación supone. Arendt no ve la relevancia del cuerpo; como tampoco el carácter interrelacional de los vínculos que aquí se establecen, que lejos de ser naturales, como todo lo humano, están transidos por la cultura; ni la importancia política de esta esfera15. Si bien es cierto que este es el ámbito que menos intromisiones de lo público acepta, que más debe ser protegido de tales interferencias, no puede bajo ningún concepto ser definido como algo sometido a las necesidades naturales (y, por ello, violentas) ni dejado al margen de lo político y de la legislación, excepto en caso de ser atacado. Por ejemplo, el maltrato o la violencia de género tienen lugar preferentemente en el espacio privado y requiere una acción política de protección a/de las víctimas, así como una mayor concienciación social y personal, y también una acción política que busque eliminar las causas de la discriminación y la desigualdad. Arendt, por su parte, cree que la ley no se aplica más que a lo político: "las leyes no pueden dictarse para un ámbito fuera del estrictamente 'político'. Me protegen de la injusticia del otro, y protegen al otro de la injusticia que yo pueda infligirle. Pero nunca han de pretender protegerme a mí de mismo, como todas las leyes contra el vicio, el juego, la embriaguez, etc. Toda irrupción de la moral o del razonamiento moralizante en la política que va más allá del concepto de la injusticia cometida contra el otro, es siempre un ataque a la libertad"16. Es decir, la alemana busca mantener la esfera privada a salvo de toda posible intromisión de lo público por lo que no destaca que en este ámbito son igualmente posibles acciones injustas contra otro. Y con ello no incide en la necesidad de aceptar una legislación de ciertas conductas o de ciertos temas que afectan a lo que ella entiende por privado, ni comprende adecuadamente que tales acciones no son lesivas de la intimidad, sino garantes de derechos. Por ello tales acciones no pueden ser calificadas de razonamientos moralizantes en política.

Del mismo modo, la alemana no percibe que el ámbito privado supone también un espacio de relaciones humanas y de libertad por lo que, como tal, ha de ser considerado igualmente desde un punto de vista público o político. Ver lo privado únicamente como un espacio sometido a la necesidad y a los ciclos biológicos supone

En Rousseau encontramos solamente: sociedad e intimidad como contraposición de aparecer y ser, de inauténtico y auténtico. Lo político, que ha de superar el 'desgarramiento', destruye tanto la sociedad como la intimidad", Arendt (2006), pp. 513-514.

15 Arendt considera que todo lo que tiene lugar en este ámbito debe resolverse al margen de la política y, por ello, no concede la suficiente importancia al hecho de que, en ciertas ocasiones, son necesarias medidas políticas para evitar situaciones de dominación o desigualdad que impiden el acceso igualitario al espacio público. De ahí que no comparta ni desarrolle el carácter emancipador del feminismo. Cfr. Guerra Palmero (2011), pp. 205-206.

16 Arendt (2006), p. 144. 
una minusvaloración inaceptable del mismo: "la satisfacción de las necesidades biológicas no puede consistir exclusivamente en el consumo de bienes perecederos, destinado a asegurar el sustento del propio cuerpo, puesto que el cuidado de la vida del cuerpo supone también la reproducción biológica del mismo, y, por tanto, la relación entre los sexos, la crianza de los niños y la atención a los enfermos y a los ancianos. Todas estas actividades forman parte de la 'labor', puesto que todas ellas tienen que ver con el cuidado del cuerpo y la satisfacción de sus necesidades biológicas, pero Arendt no les presta la menor atención en su fenomenología de la vita activa"17. Frente a Arendt, hay que reconocer que en todas las actividades relacionadas con la vida, la crianza y la atención a las personas, están implicadas la acción, el discurso y la amistad; es decir, el amor mundi ${ }^{18}$. No son ni pueden ser reducidas a una actividad cíclica que se atiene a las necesidades biológicas y naturales. Además, quién, cómo y a costa de qué se ocupa de ello es indudablemente una cuestión política de primer orden.

El planteamiento arendtiano que establece una diferencia radical entre público y privado no solo deja sin protección legal al ámbito doméstico, sino que pierde de vista la importancia pública, así como privada, de la corporalidad. Atendiendo al objetivo de su pensamiento (la rehabilitación de la política), es normal que la alemana no prestara la suficiente atención al estudio de la esfera doméstica, a las diferentes actividades que allí se realizan, a sus peculiaridades y a su profunda vinculación histórico-social con lo femenino y, más concretamente, con la corporalidad femenina. La alemana, al relegar, el ámbito de lo privado a la satisfacción de las necesidades biológicas descuida el papel de la libertad en las relaciones del ser humano consigo mismo y con los seres que aparecen en su espacio privado, con los que convive en libertad y con los que también emprende acciones en concierto. Sin embargo, lo que es más problemático es la falta de consideración de todo lo que sea corporal en el ámbito público. Arendt busca establecer un espacio de aparición que garantice el igual ejercicio de la toma de palabra y la realización de acciones en concierto y, al hacerlo, entiende los sujetos políticos como sujetos sin corporalidad, sin trasfondo social, lingüístico, racial... A pesar de la conveniencia y necesidad de garantizar la igualdad política, lo cierto es que los sujetos políticos solo son iguales desde un punto de vista formal, pero son muy diferentes desde otros que, en mi opinión, no pueden ser calificados únicamente como personales o sociales. La toma de decisiones, la acción conjunta, el ejercicio de la libertad, tienen como sujetos a seres humanos encarnados, inscritos en tradiciones y comunidades; y esos son aspectos importantes en su vida pública y que, a la vez, han de ser tenidos en cuenta por la política, sea vista como acción conjunta o como ejercicio de la soberanía en las democracias representativas. No se toman decisiones sobre lo común como si uno

17 Campillo (2002), p. 171.

18 Cfr. Kristeva (2001a), pp. 183-184. 
fuera un sujeto sin cualificaciones ni se legisla sobre sujetos homogéneos. Por ello hay que atender a todas estas dimensiones que son políticas y afectan al ejercicio de lo político.

Cuando Arendt aborda mínimamente la aparición de estos temas en la esfera pública, une el cuerpo a los ciclos naturales y se niega a reconocer su papel político: "el hecho de que la Edad Moderna emancipara a las mujeres y a las clases trabajadoras casi en un mismo momento histórico, ha de contarse entre las características de una época que ya no cree que las funciones corporales y los intereses materiales tengan que ocultarse. Lo más sintomático de la naturaleza de estos fenómenos estriba en que los pocos residuos de lo estrictamente privado se relacionan, incluso en nuestra propia civilización, con las 'necesidades', en el sentido original de ser necesarias por el hecho de tener un cuerpo"19. Esta aparición supuso, según la alemana, simplemente hacer público lo que era privado y poner ante la vista actividades vinculadas con las necesidades biológicas ${ }^{20}$. Es decir, Arendt no concede ningún papel político a estas dimensiones.

Ante estas afirmaciones habría que recordar, en primer lugar, que la relación del ser humano con su cuerpo es sumamente compleja y, en gran parte, cultural o construida. Ello significa, como señala Sánchez Muñoz, que se puede convertir lo fáctico en objeto de diálogo y hacer de lo personal algo político ${ }^{21}$. Además, el cuidado del cuerpo tampoco es simple labor. Por eso algunos intérpretes han dicho que Arendt reconoce la corporalidad, pero no sabe qué hacer con ella porque cuando el sujeto se centra en el cuerpo pierde de vista el mundo. Es decir, aunque Arendt reconoce que lo privado es necesario porque da una calidad vital22, después no profundiza en este tema. La pensadora no atiende a aspectos relevantes de la corporalidad, pues solo ve su carácter funcional, con lo que pierde de vista otras dimensiones de la misma 23 que, a pesar de lo que ella afirma, son aspectos que integran y definen al sujeto político. Arendt simplemente centra su atención en la política, pero tiene

19 Arendt (1993), p. 78. Esta relegación del cuerpo está vinculada con la diferencia entre quién y qué. Cfr. Kristeva (2001a), p. 174, 177, 178, 179, 182. Arendt ve con recelo la aparición de este ámbito en público y lo relaciona con la sociedad y el auge que la economía experimenta en la edad moderna: "la emancipación de la clase trabajadora significa esencialmente no el dominio de las masas, sino: el hecho de que el trabajo se consideró como algo público y político. Trabajar dejó de ser una cosa privada y se convirtió en una actividad pública, Y esto significó dos cosas: I. que la necesidad se introdujo en la acción política [...] 2. Que se hizo público lo esencialmente privado de la mera vida biológica, a saber, el proceso de la combustión de lo biológico, que descansa en el consumo y no es posible para el hombre sin trabajo: metabolismo con la naturaleza", Arendt, (2006), p. 413.

20 Cfr. Arendt (1996), pp. 199-200.

21 Cfr. Sánchez Muñoz (1994), p. 36. Para Arendt el cuerpo está marcado más por su destino mortal que por su sexo. Cfr. Zerilli (1995), p. 172.

22 Arendt (1996), p. 198.

23 Cfr. Collin (1992), p. 25. Según esta autora, Arendt tampoco ve el carácter simbólico de lo gestual y excluye de lo cultural la ritualidad. Cfr. p. 24. 
una noción de política sumamente estrecha. En segundo lugar, como expondremos en el próximo apartado, habría que revisar su concepción del mundo moderno como un proceso de ascenso de lo social que supone la identificación de la economía con la labor, con las actividades que se ocupan de la satisfacción de las necesidades biológicas, ya que es muy difícil aceptar tal concepción de lo económico.

Para Arendt, por tanto, ser mujer no es una diferencia política, sino básicamente algo natural, algo dado. De ahí que, como se ve en su correspondencia con sus amistades, no sintiera ninguna afinidad con los movimientos feministas ni participara en ninguna lucha por los derechos de las mujeres. Así pues, en la diferencia público/privado queda "atrapado" el cuerpo y las actividades relacionadas con él, y todo ello es identificado con la naturaleza, no con la cultura ni la política. Esto supone que lo privado no es ni debe ser, para Arendt, hecho público, con lo que pierde de vista que qué sea lo privado es definido, en gran parte, por lo público: "por la fórmula 'lo privado es político' las feministas intentaban recordar que la estructura de lo privado no es autónoma, sino que está regida por un imperativo político"24. Es decir, esta rígida separación arendtiana implica no ver el carácter construido de la identidad privada y el modo cómo está constituida por lo público25. Igualmente tampoco permite captar la manera en la que la identidad privada afecta a lo público y a lo político. El espacio político que propone Arendt requiere e impone homogeneidad, lo que excluye los aspectos corporales y afectivos, además de los sociales, de esta esfera. Pero en la realidad eso no se produce nunca del modo en el que ella lo expone.

Por otra parte, este planteamiento significa asumir una definición de la identidad corporal "cerrada", al margen de la iniciativa y la acción 26 , ya que solo se reconoce su papel político cuando se es atacado por algún rasgo que es y debería seguir siendo privado y natural27. Pero no contempla la posibilidad de que la libertad humana revierta sobre la naturaleza, aceptándola o modificándola; en el fondo, creando una identidad narrativa que afectaría a la totalidad del sujeto y no únicamente a su aparecer público. Para Arendt solo el espacio de aparición permitirá al ser humano mostrar quién es, puesto que la identidad humana (lo que tiene que ver con el bios y no con la zoé) lejos de ser algo ya logrado, es una identidad construida,

\footnotetext{
24 Vicente Arregui (2011), p. 231.

25 "Initially, feminist constructivists forged this distinction to facilitate the emancipator claim that gender is not a biological mandate but a socially imposed role", Disch (1995), p. 287.

26 "The danger is not in focusing on identity per se, but in regarding it as static, and neglecting to link it explicitly to political action", Bickford (1995), p. 314. Arendt no ofrece una política basada en la identidad, por lo que su noción de acción sirve para atacar toda política de la identidad cerrada y abrir un nuevo discurso. Cfr. p. 35. Sin embargo, deja la identidad corporal como algo inmodificable y, lo que es peor, reducida a puros ciclos biológicos y necesarios. No ve, por tanto, el carácter social y político de tal reducción.
}

27 Cfr. Disch (1995), p. 287. 
una identidad narrativa. De ahí la necesidad del relato de la vida propia, de la biografía, que es realizada por el espectador. El ser humano es agente, actor que ejecuta la acción y toma la palabra para definirse a sí mismo y definir/crear el espacio público con otros. Y en este sentido, a pesar de que Arendt no lo desarrolle con la atención que merece, la "construcción" de la identidad está marcada por aspectos culturales tanto por el lado del actor o actriz como por el del espectador o espectadora, y afectaría igualmente a la construcción de lo privado. La alemana, en cambio, incide únicamente en que el ser humano inicia la acción, pero el curso de esta está fuera de su control: es imprevisible porque interactúa y se cruza con otros cursos de acción. Por último, es claro que para Arendt no toda forma de convivencia es política o artificial, sino que hay algunas que son naturales ${ }^{28}$. De ahí que su modo de organización y sus criterios para lidiar con estos problemas no sean ni deban ser políticos. Ahora bien, esta separación tan tajante de lo político y lo natural es más bien artificial, no hace justicia a lo que ella denomina privado y pierde de vista aspectos importantes que son propiamente políticos.

\section{La exclusión de lo social de la política}

La creación de este espacio político asentado en la diferencia entre lo público y lo privado, entre lo biológico y lo creado por el ser humano, se completa con la distinción entre lo social y lo político. Son muchos los intérpretes que han señalado que hay que considerar de nuevo la delimitación de lo político frente a lo natural29, así como su tajante separación respecto a lo social, pues "si no hay hombre en general, si no existimos como alguien más que protegidos por una ciudadanía, tal como lo precisa Arendt, hace falta añadir que nadie es ciudadano en general, sino un ciudadano concreto inscrito en una pertenencia comunitaria, sólo a partir de la cual puede elaborarse un mundo en común" 30 . Y por ello algunos aspectos que Arendt estima que son sociales tendrían que ser considerados desde un ángulo político. En este punto es aún más patente que una separación rígida y a priori de ámbitos es artificial e impide comprender adecuadamente la complejidad de la vida política, donde

\footnotetext{
28 Cfr. Birulés (2007), p. 75. Es necesario destacar que con la figura del paria la diferencia público/privado deja de ser tan rígida. Cfr. p. 36.

${ }^{29}$ En esta dirección se dirige la crítica de Paul Ricoeur a Arendt. Cfr. Ricoeur (1991), p. 146. El tema de la natalidad es, por otra parte, uno de los que mayor recepción ha tenido entre algunas feministas. Por otra parte, como bien señala Sánchez "el concepto de natalidad sería uno de esos conceptos 'puente' presentes en su obra que nos muestran cómo las indicaciones que aparecen en principio de manera rígida nos muestran también continuidades entre ellas. Así, la natalidad nos revelaría cómo para Arendt en último término la distinción público-privado es más permeable y porosa de lo que aparenta ser en principio", Sánchez Muñoz (2003), p. 168.

30 Collin (1992), p. 38.
} 
nadie es únicamente ciudadano en abstracto. Si bien la alemana apuesta por una nítida autonomía de lo político, buscando de este modo rehabilitar esta actividad, considero que tal delimitación no puede ser aceptada tal cual. Tanto lo social como lo económico forman parte de lo político. Solo la separación que la alemana traza en la Condición humana entre tres tipos de actividades (labor, trabajo y acción) y su posterior identificación de la política con la acción exige que la labor y el trabajo queden al margen de la política, cosa que, atendiendo al decurso del mundo moderno y del actual, se ve como falsa.

Además, me parece que es conveniente examinar críticamente lo que suponen esas distinciones por las que lo social es el ámbito de las diferencias ${ }^{31}$ y lo político el de la igualdad; lo que implica que las diferencias sociales deben ser resueltas en un ámbito distinto al político, como se ve en su artículo sobre Little Rock ${ }^{32}$. Arendt acepta que cuando una diferencia personal o social es atacada ha de haber también una respuesta política: "así como el gobierno no tiene ningún derecho a interferir en los prejuicios y las prácticas discriminatorias de la sociedad, no sólo tiene el derecho, sino la obligación, de asegurar que dichas prácticas no se impongan legalmente. Exactamente igual que el gobierno ha de garantizar que la discriminación no atente nunca contra la igualdad política, debe también salvaguardar los derechos de toda persona a hacer lo que quiera entre las cuatro paredes de su casa. [...] El gobierno no puede, legítimamente, tomar medidas contra la discriminación social porque el gobierno sólo puede actuar en nombre de la igualdad, principio que no rige en la esfera social" 33 . Sin embargo, lo que demanda es que todos estos asuntos se resuelvan en un plano social y no político. De este modo, si bien no estaría excluyendo a priori una actuación política encaminada a disminuir las diferencias u obstáculos que impiden el igual acceso al espacio público, no propondría políticas activas ni positivas para reforzar la desaparición de prejuicios que ella juzga que son sociales. Para la alemana la política es la aparición en un espacio público que garantiza la igualdad y el derecho a tener derechos, pero no toma en consideración, sino que más bien critica -como se ve en su exposición sobre la Revolución Francesa- que la liberación, y la garantía del acceso al espacio político tengan que ser una de las funciones de la política.

\footnotetext{
31 Cfr. Kristeva (2001a), p, 114.

32 "Similarly, laws preventing desegregation of schools and other public facilities seemed to Arendt to be obviously unconstitutional, contrary to the principle of equal laws for citizens. Within that framework of equal laws, however, it seemed to her dangerously foolhardy to try to enforce social equality. Blacks and whites should not be prevented by law from marrying one another, but they could not be forced by law to do so: and similarly, while children of different races should not be prevented by law from attending mixed schools, they should not be forced to do so either", Canovan (1992), p. 243.

33 Arendt (2007), p. 199.
} 
Los problemas en este punto se incrementan por la falta de precisión de Arendt en el uso del término social: "lo social es un concepto complejo y altamente confuso, que no presenta un significado unívoco, sino que despliega distintos referentes a lo largo de su obra. [...] Según Seyla Benhabib, el término 'social' hace referencia a lo largo de su obra a tres procesos sociales, diferentes, pero interrelacionados: En primer lugar, a la aparición de las relaciones propias del mercado de cambio en una economía capitalista, significado presente en La condición humana. En segundo lugar, 'social' haría alusión a la aparición de la sociedad de masas, con unos modelos de conducta, acciones y mentalidades propios. Este referente lo encontramos en Los orígenes del totalitarismo y en La condición humana. Por último, tendríamos aquel significado presente en sus primeros escritos, sobre todo en Rahel Varnhagen, que se referiría a los procesos sociales y culturales de asociación, interacción y sociabilidad que aparecen en la transición del Antiguo Régimen a la Modernidad" 34 . En la Condición humana, Arendt señala que lo social proviene de societas, que es una alianza para un propósito específico. Igualmente indica que es un fenómeno moderno, que supone el ascenso de lo económico, el hogar, y su exhibición en el ámbito público ${ }^{35}$. Por tanto, la sociedad es la organización pública del proceso vital y, como tal, está vinculada a la necesidad o mutua dependencia para garantizar la vida. El problema es que lo social tiende a crecer y devorar los ámbitos públicos y privados ${ }^{36}$ porque produce la liberación de un proceso natural que es el proceso vital de la sociedad: esto sucede en diferentes estadios culminando, según ella, en una sociedad masificada y burocratizada.

Esta concepción de lo social como relaciones económicas -actividades dirigidas a cubrir las necesidades de la vida- junto a la visión de la sociedad masificada que tiende a imponer un fuerte aislamiento de los seres humanos que quedan atomizados y, finalmente, encerrados en su vida privada, refuerza para la alemana la necesidad y urgencia de separar la política de lo social. Por otra parte, lo social, para Arendt, supone un espacio en el que las diferencias cuentan y han de ser fomentadas, y especialmente un espacio intermedio entre lo privado y lo público ${ }^{37}$. Este es un ámbito en el que se muestra en público lo que es privado, lo que está vinculado a lo biológico y al mantenimiento de la vida, por tanto, a lo económico; es un espacio que, como tal, tiende a crecer indefinidamente, lo que produce una degradación tanto de lo público como de lo privado: “¿cuáles son las formas políticas en las que se manifiesta lo social? Según Arendt, estas son la nación-estado y la burocracia [...]

\footnotetext{
34 Sánchez Muñoz (2003), p. 275. En la separación de lo político y lo social, bien sea visto como actitudes (Benhabib) o como contenidos (Sánchez) es donde radican muchos problemas de su teoría. Cfr. p. 176.

35 Cfr. Pitkin (1998), p. 11.

36 Cfr. Pitkin (1998), p. 14.

37 Arendt (2007), p. 196.
} 
El triunfo de la burocracia significa, en este sentido, el triunfo de la sociedad, como un sujeto colectivo uniforme que -como un ente expansivo- presenta 'una irresistible tendencia a crecer, a devorar, las más antiguas esferas de lo público y lo privado""38. Arendt ve estos aspectos del mundo moderno como elementos característicos del totalitarismo y, por ello, los teme y rechaza con tanta vehemencia. Al insistir en esto, la alemana pierde de vista otros aspectos relevantes del mundo moderno.

Lo social y lo económico estarían, según Arendt, vinculados a la vida y no a la pluralidad. Pero esto, en el fondo, puede ser visto como una mera petición de principio: es la definición arendtiana de la política como ámbito de libertad, de acción concertada, de actividad no medial, la que impide que todo esto sea visto como político. Es más, la comprensión arendtiana de lo económico no se ajusta al papel que la economía juega en las sociedades actuales. Con esta tajante separación de lo social-económico respecto a lo político parece muy difícil lograr una adecuada comprensión de nuestras sociedades. Igualmente habría que decir que su miedo a los procesos de masificación no justifica la exclusión de lo social y las diferencias del espacio de aparición público y de la acción de la libertad. Por último, es necesario recordar que la delimitación de lo social y lo político, así como la determinación de lo que es una necesidad humana es una cuestión política. Nuevamente la separación en ámbitos o actividades impide ver correctamente la articulación de los mismos tal como se da, de hecho, en la realidad.

\section{Los problemas de la delimitación de lo político}

Al abordar la política en la obra de Arendt, lo primero que destaca es que no ofrece un único sentido para esta noción. En un artículo excelente Antonio Campillo señala, por un lado los posibles motivos de esa polisemia y, por otro los tres significados que Arendt otorga al término a lo largo de su extensa obra. Entre los motivos está, en primer lugar, el conocido rechazo arendtiano a crear un sistema filosófico o teórico; es decir, su intento de reflexionar mediante ejercicios de pensamiento, teniendo en cuenta el contexto o el debate histórico y buscando rescatar las perlas y el coral de las experiencias pasadas ${ }^{39}$. Ella misma decía que su lema era pensar como si nunca nadie hubiera pensado y luego pensar con los demás, lo que supone que su reflexión aborda los problemas de un modo histórico, que no pierde de vista el contexto en el que se enmarca cada experiencia estudiada, lo que, a su vez, ofrece una gran riqueza a su pensamiento, pero produce también una dispersión en el uso de los términos. Este modo de reflexionar no da lugar a una teoría general ni a un estudio más concreto o sistémico del modo en el que se articulan o podrían arti-

38 Sánchez Muñoz (2003), p. 281.

39 Cfr. Arendt (1983), p. 196. 
cularse los sentidos que se cruzan, superponen o incluso contraponen en sus diferentes ejercicios. Es decir, cuando su amiga Mary MCarthy le señaló que su manera de pensar era muy escolástica, por contraposición de categorías (a veces binarias o a veces ternarias), ella simplemente contestó que aceptaba tal observación, pero que, en realidad, ese era un hábito de pensamiento aristotélico ${ }^{40}$. Lo que, sin embargo, no hizo fue algo parecido al libro V de la Metafísica de Aristóteles. No ofreció definiciones ni una sistematización.

A esto hay que añadir que su reflexión política se vertebra, en gran parte, en torno a su debate crítico con la filosofía política ${ }^{41}$. Arendt trata de salir del marco de la filosofía que nace con Platón y conduce hasta Marx, visto como el último representante de la tradición. La filosofía política, que se ha alejado de la experiencia y de los verdaderos hombres políticos, ha cometido graves errores: ha pensado la vida activa desde la vida contemplativa imponiendo la tiranía de la verdad, y la praxis desde la poiesis dando lugar a la producción de la política42; en el fondo, ha confundido el poder con la soberanía y el control de la violencia legítima, y ha olvidado los rasgos característicos de los asuntos humanos: la fragilidad, la imprevisibilidad y la irreductibilidad. De ahí que en algunas de sus obras se mezclen los sentidos tradicionales de las nociones políticas con los que ella está otorgando a esos conceptos. Por último, hay que destacar dos movimientos contrarios en la obra de Arendt: la generalización de la política como rasgo propio de todos los seres humanos, ya que está vinculada con la ley de la tierra, la pluralidad y la natalidad; y a la vez, la restricción de la política, pues su sentido se daría únicamente en la acción, el discurso y el poder como acción concertada.

Teniendo en cuenta este marco teórico que explica la falta de consideración de ciertos problemas, especialmente los que afectan a las transiciones y a la discontinuidad entre ámbitos, se pueden tomar en consideración los sentidos del término. El más general es el que presenta la política como un espacio de aparición, como un lugar de carácter casi ontológico en el que aparecen los diversos seres humanos, lo que les permite alcanzar su identidad narrativa. Por la acción y el discurso los seres humanos se presentan o aparecen ante otros y en ese espacio trascendental que es una web de relaciones basadas en la aparición -ver y ser visto- se desarrollan las vidas humanas, se entretejen las narraciones y se logra la estabilidad del mundo humano (diferente de la tierra) así como la inmortalidad terrena ${ }^{43}$. Estas considera-

\footnotetext{
40 Cfr. Arendt (1995), pp. 170-171.

41 Arendt considera que la filosofía no sabe qué es la política, ya que ha olvidado la pluralidad. Cfr. Arendt (2006), p. 15.

42 "Understanding politics in terms of 'work' might be dangerously hubristic, but was at any rate humanist, whereas thinking in terms of 'labour' meant surrendering human values altogether. For the crucial feature of labour is that it is the least free aspect of human activity", Canovan (1992), p. 74. 43 Cfr. Arendt (1993), capítulo 25: la trama de las relaciones y las historias interpretadas.
} 
ciones tan presentes en La condición humana otorgan a la política un sentido trascendental, vinculado a la condición humana, más concretamente, a la natalidad como segundo nacimiento.

Pues bien, en este primer sentido ya aparece un serio problema en la definición de la política en su relación con lo no-político: "por un lado, el 'espacio de aparición' es esa apertura espacio-temporal que los humanos compartimos con todos los seres sensibles, e incluso con el conjunto de los seres naturales, en cuanto que todos formamos parte de un mundo plural y cambiante, diverso y contingente; por otro lado, el 'espacio de aparición' es ese mundo específicamente humano que una determinada comunidad de seres vivientes instituye al decir 'nosotros', y que la separa no sólo del resto de la naturaleza sino también de todas las otras comunidades humanas que dicen igualmente 'nosotros'. Ante esta paradoja constitutiva de la humana experiencia del mundo, el razonamiento de Arendt es confuso e incluso contradictorio: la autora reconoce la continuidad ontológica entre los humanos y el resto de los seres naturales, en el seno de un mundo plural y contingente, pero al mismo tiempo recurre al viejo dualismo metafísico y postula una nueva jerarquía sólo parcialmente inversa a la jerarquía metafísica tradicional- entre el oscuro reino de la necesidad natural y el luminoso reino de la libertad humana, entre el 'conocimiento' técnico-científico que se ocupa del primero y el 'pensamiento' ético-político que se ocupa del segundo" 44 . Esta diferencia que busca realzar el valor de lo humano y de la libertad pierde de vista que la aparición en público constituye comunidades y no un espacio único y global - cosa que, por otra parte, ella temía y rechazaba- y establece una dualidad excesivamente rígida entre necesidad-naturaleza y libertad-humano.

En el análisis de la vida activa realizado en La condición humana surge un segundo sentido de la política, en este caso restrictivo, unido a la diferencia entre labor, trabajo y acción que le lleva a buscar la autonomía de la política respecto a las otras actividades, especialmente respecto a la confusión de la labor-trabajo; es decir, de la confusión que, según ella, ha cometido la filosofía política: ver la praxis desde la poiesis. Aquí aparecen una amplia gama de consideraciones en torno a la política, desde las que inciden en la concepción estética de la praxis, vista como una actividad desinteresada, realizada con otros, autofinalizada y totalmente opuesta a toda actividad instrumental; hasta las que ponen de relieve la tajante separación de lo social-económico respecto a lo político y las que señalan el carácter no instrumental o no medial de la política. Dado el objeto de este texto, me centraré únicamente en la crítica arendtiana a la confusión de la política con la economía. Como se ha señalado antes y es bien sabido, la americana realiza una lectura del mundo moderno en la que pone de relieve que se ha producido un ascenso vertiginoso de

44 Campillo (2002), pp. 166-167. 
lo social, visto como una ampliación de lo privado, que se ha realizado en diferentes etapas y que ha producido, al menos, dos grandes problemas: la aparición de la sociedad masificada y el triunfo del homo oeconomicus, lo que conduce a la consideración de las necesidades y de la vida biológica como uno de los aspectos claves de la política. En esta crítica que rechaza tanto la biopolítica como toda doctrina que considere las relaciones económicas como básicas, Arendt excluye lo social y lo económico del ámbito de la política.

Este es uno de los puntos en los que se ve más claramente la limitación de su pensamiento: la autonomía de la política definida como acción reclama dejar fuera de la política las cuestiones sociales y las económicas. Es decir, no tiene en cuenta la justicia social 45 ni la relevancia que todo lo social y lo económico tiene para la política. Arendt, como hemos señalado, cree que esos son ámbitos sujetos a la necesidad, a las diferencias y a la promoción de las diferencias, y añade que son regulados por un pensamiento de tipo medios-fines o instrumental por lo que pueden ser resueltos por expertos 46 ; es decir, no son debatibles ni, como tales, políticos. Si bien es cierto que señala que casi todos los asuntos tienen diversas dimensiones (políticas, sociales, económicas), su división y categorización ofrece serias dificultades a la articulación de los planos y parece ofrecer una visión estanca de cada ámbito. Por ejemplo, no ve que la labor está conectada con las relaciones familiares y domésticas, pero también con las sociales o simplemente intersubjetivas ${ }^{47}$; que el trabajo es inseparable de la economía y la reproducción cultural. Igualmente tampoco destaca la necesidad del trabajo para la conservación y trasmisión de la propia acción, bien en su institucionalización bien en su narración. Es decir, no atiende de un modo correcto a las formas de articulación de las tres actividades: "frente a esta jerarquía antropológica, creo que es imprescindible postular tres tesis interrelacionadas. Primero: la 'acción' y el 'discurso' están presentes en las tres esferas de la vita acti$v a$, y en cada una de ellas dan lugar a un tipo particular de relaciones sociales (parentales, económicas y políticas). Segundo: estas tres formas de relación social no hacen sino modelar 'culturalmente' otras tantas condiciones 'naturales' de la vida humana [...], así que las tres son simultáneamente 'naturales' y 'culturales', las tres realizan el tránsito y la simbiosis entre la animalidad y la humanidad. Tercero: estas tres relaciones son a un tiempo irreductibles e inseparables entre sí, así que no cabe establecer entre ellas ninguna relación de derivación unilateral, ni tampoco ninguna jerarquía de humanidad o de excelencia, pues las tres son igualmente imprescindibles en la constitución y preservación de cualquier sociedad humana"48.

\footnotetext{
45 Cfr. Passerin d'Entrèves (1994), p. 61.

46 Arendt sostiene que se resuelven por medio de la tecnología. Cfr. Arendt (1988), p. 60.

47 Sí ve que se relaciona con el trabajo. Cfr. Arendt (2006), p. 303.

48 Campillo (2002), pp. 172-173.
} 
La falta de atención a las articulaciones entre las tres actividades se pone de relieve al ver el escaso desarrollo teórico de la necesidad de estabilización y de reificación de la acción, que para crear un mundo humano ha de dar lugar a un espacio permanente $\mathrm{y}$, por ello, marcado por la presencia de instituciones y legislaciones, que Arendt suele mirar con cierto recelo, pues tenderían a limitar la participación ciudadana y la libertad de iniciativa. De ahí su apoyo a la revolución permanente, y no solo espontánea, al sistema de consejos y a una política federal49. No obstante, esa reificación en la que juega un papel clave el trabajo, y no únicamente la acción, es sumamente necesaria para la política. Por otra parte, esta falta de atención se ve en la crítica al marxismo por confundir la labor y el trabajo ${ }^{50}$. Arendt no capta el sentido que Marx otorga al trabajo como acto de libertad ${ }^{51}$ y el papel que juega la economía en la política. La alemana tiende a reducir la labor a algo que tiene lugar en el plano doméstico, que únicamente cubre necesidades biológicas y está sometido al interminable ciclo biológico. Marx, en cambio, incide en el carácter social de la labor y en su productividad y valor ${ }^{52}$. Además, Arendt no comprende la estrecha relación del trabajo y la labor, por ejemplo, en la conservación de las obras de arte 53 . Tampoco ve que la economía se entiende mejor en términos de trabajo (producción de toda la infraestructura material) que en términos de labor ${ }^{54}$. $\mathrm{Ni}$ que la economía capitalista es también una estructura de poder 55 .

La no consideración de las articulaciones o simplemente su incorrecta comprensión ha llevado a la alemana a no ver que tanto lo doméstico como lo económico son problemas políticos de primer orden y que considerarlos desde el ángulo polí-

49 Cfr. Arendt (1988), capítulo 6: "La tradición revolucionaria y su tesoro perdido".

50 "All of Arendt's specific charges against Marx have some foundation in the texts, yet almost all of them involve misreadings and distortions, sometimes blatant ones. Begin with the central idea of Marx's alleged obsession with labor, his neglect of work. Marx of course wrote in German, and although Arbeit does translate the English 'labor', it is by no means, as Arendt misleadingly claims, the German equivalent for 'labor',' for the two languages do not encode quite the same distinction. The range of words in the werk-family in modern German is extremely restricted. The verb, as Arendt notes, has become 'rather obsolete', leaving only arbeiten for translating both 'to labor' and 'to work'. And the noun, as Arendt fails to note, refers only to the product or result, so that only Arbeit is available for the process of production, be it labor or work. Marx's frequent use of the words from the arbeit-family, therefore, cannot indicate a preoccupation with labor to the detriment of work. On the contrary, except where context indicates otherwise, when Marx says Arbeit or arbeiten he is just as likely to mean work as labor, or both together. Arendt is thus wrong to read Marx as if he had a choice between work and labor and opted for the latter; and she is doubly wrong, to conclude that he must caught in 'contradictions', or reluctantly forced to admit' something, or 'misrepresenting' labor as work”, Pitkin (1998), pp. 133-134.

51 Cfr. Pitkin (1998), p. 138.

52 Cfr. Pitkin (1998), pp. 135-136.

53 Cfr. Canovan (1992), pp. 124-125.

54 Cfr. Passerin d'Entrèves (1994), p. 60.

55 Cfr. Passerin d'Entrèves (1994), pp. 60-61. 
tico supone una revalorización de los mismos: "al describir este proceso de modernización como el 'auge de lo social', Arendt lo interpreta exclusivamente en términos negativos, como una expansión de lo privado a costa de lo público, esto es, como una subordinación de lo político a lo económico y a lo doméstico, pero no es capaz de percibir que también se produce un movimiento inverso: la politización de las relaciones sociales hasta entonces despolitizadas, esto es, la puesta en cuestión de la explotación económica entre las clases y de la dominación patriarcal entre los sexos. Arendt parece no comprender que las cuestiones económicas y domésticas son políticamente relevantes, desde el momento en que pueden posibilitar o dificultar el acceso de los trabajadores y de las mujeres al espacio público de los iguales. [...] Por tanto, el modo concreto en que se articulen lo político, lo económico y lo doméstico en una sociedad determinada, es en sí mismo un problema político, más aún, es el problema político por antonomasia, puesto que concierne a la constitución de esa sociedad en cuanto comunidad política" 56 . Es decir, el uso de categorías y ámbitos estancos impide ver la riqueza de las relaciones humanas y la adecuada articulación de lo natural y lo cultural, pues la capacidad de crear cultura y de modificar la naturaleza -la externa y la propia- es más amplia que lo que la alemana atribuye a la acción ${ }^{57}$ y no siempre que se produce un "trasvase" de una actividad a otro ámbito tiene lugar una alienación o una pérdida.

El último sentido de la política que opera en los textos de Arendt destaca su carácter único, ya que la acción y el discurso no parecen ser suficientemente distintivos para identificar la política ${ }^{58}$. Esta actividad ha sido descrita, desde la tradición filosófica, como la organización del poder legítimo de una comunidad. Arendt se opone a esto e incide en que el poder es acción concertada y solo dura lo que dura esa comunidad 59 , en que la política no puede apelar a una lógica de medios-fines ${ }^{60}$, en que el poder no solo es diferente, sino opuesto a la violencia, y en que el gran riesgo de toda acción política es su cosificación con la consiguiente disminución del espacio público y de la participación ciudadana, lo que llevaría a la pérdida del poder que reside en el pueblo entendido como sujetos que realizan una acción de modo concertado y mientras actúan de este modo. Es decir, el acto político por

56 Campillo (2002), p. 173.

57 Sin embargo, Arendt lo reconoce: "deseo refutar la oposición que planteas entre cultura y naturaleza. Cultura es siempre naturaleza cultivada: de la naturaleza se ocupa y se cuida uno de los productos de la naturaleza llamado hombre. Si la naturaleza muere, también morirá la cultura, y con ella todos los artefactos de nuestra civilización”, Arendt, McCarthy (1998), p. 347.

58 Es más, "action, even as Arendt understands the term, cannot by itself guarantee a free and creative life", Kristeva (2001a), p. 42.

59 Cfr. Arendt, (2006), p. 25.

60 En primer lugar, porque esta dinámica solo trata con los medios o lo convierte todo en medio y, en segundo, porque tal lógica degrada la naturaleza. Cfr. Arendt (2006), p. 57. Y por último, porque producirá la transformación del propio hombre en un medio. Cfr. p. 121. 
excelencia es la revolución, que la alemana no ve como un acto violento de liberación, sino como un ejercicio conjunto de creación de un espacio público en el que se busca la felicidad o el bien público. Así vista, la acción política es un acontecimiento excepcional y milagroso, que, como muestra su estudio de las revoluciones francesa y americana, así como de la húngara, tarde o temprano acaba fracasando.

Esta oposición a la noción tradicional de la política y del poder supone una revisión del concepto de soberanía, del problema de la legitimación de la constitución y de los llamados aspectos estratégicos de la política. No solo la oposición entre poder y violencia deja abiertos muchos interrogantes, pues la violencia también es acción concertada y el poder concertado puede ser violento y producir una fuerte represión de las minorías y una eliminación de toda diferencia, ya que lo característico de la polis es la igualdad artificial61. Esta oposición también muestra muy bien la necesidad de realizar una reflexión sobre las instituciones políticas, sobre los elementos estratégicos de todo poder62 y sobre la forma representativa de todas las democracias actuales 63 . Aquí se inscribe la crítica de Habermas a Arendt por entender la política como fin en sí misma desligada de los elementos estratégicos por ser violentos; y por apartar esta actividad de sus relaciones con su entorno económico y social, así como por no dar cuenta de la violencia estructural ${ }^{64}$.

Si bien es cierto que en períodos de crisis se ve una mayor participación ciudadana, una mayor concienciación de la necesidad de tomar parte en la política, lo que está unido a un fuerte descrédito de la actividad política y más concretamente de los políticos, también es patente que todos los países democráticos tienen un poder representativo que se desarrolla y canaliza de modo institucional. No atender a esta dimensión de la política es una gran limitación o incluso un grave error de una teoría política que busca comprender lo que sucede y no perder experiencias políticas valiosas. De ahí las dificultades que surgen al aplicar su teoría a las sociedades modernas: "como señala certeramente Jünger Habermas, las propuestas arendtianas presentan una tremenda paradoja, y es que por un lado nos permiten percibir fenómenos o experiencias del mundo moderno para los que la ciencia política se ha

61 "La política organiza de antemano a los absolutamente diferentes de cara a una igualdad relativa y a diferencia de los relativamente diferentes", Arendt (2006), p. 18. La concepción de Arendt sobre el uso de la violencia implica que ha de ser medial y limitada. Cfr. Bar On, Bat-Ami (2002), pp. 157158.

62 La alemana no atiende a la dimensión estratégica de la política que es diferente de la instrumental. Cfr. AA. VV. (1987), pp. 90-91.

63 "Arendt would strongly agree that a republic does need a constitutional structure of laws and institutions, but these are not the focus of her attention. She wishes above all to correct the misleading emphasis of traditional thinking, and to stress that free politics is not only something that is artificial rather than natural, but also something that is not made by an artificer but that appears among plural men", Canovan (1992), p. 208.

64 Habermas (1975), pp. 214-215. 
hecho insensible. Pero por otro lado, sientan las bases de una concepción de lo político que puede llevarnos a ciertas incongruencias al intentar aplicarlas a las sociedades modernas" 65 .

Como se ve, la teoría política de Arendt, tal y como ella misma pretendía, deja abiertos muchos temas y sin resolver algunos problemas inherentes a su modo de categorizar y separar actividades y “ámbitos” humanos. Por ello es necesario ir más allá de su planteamiento e integrar correctamente las relaciones entre naturaleza y libertad; entre personal, social y político; entre público y privado; entre economía y política; entre acción e institucionalización de la misma; y entre actividad de los sujetos políticos y poder soberano de un Estado.

\section{Referencias bibliográficas}

ARENDT, H. (1988): Sobre la revolución, Madrid, Alianza.

Arendt, H. (1995): De la historia a la acción, Barcelona, Paidós.

Arendt, H. (1995): Men in Dark Times, San Diego, New York, London, Jovanovich.

ArendT, H. (2006): Diario filosófico 1950-1973, Barcelona, Herder.

Arendt, H. (1993): La condición humana, Barcelona, Paidós.

ArendT, H. (1996): Entre el pasado y el futuro, Barcelona, Península.

ArendT, H. (2007): Responsabilidad y juicio, Barcelona, Paidós.

Arendt, H.; McCarthy, M. (1998): Entre amigas. Correspondencia entre Hannah Arendt y Mary McCarthy 1949-1975, Barcelona, Lumen.

AA.VV. (1987): La pluralité irrepresentabile. Il pensiero politico de Hannah Arendt, Urbino, Quattroventi.

BAR ON, B. (2002): The Subject of Violence, New York, London, Rowma \& Littleflied Publisher, Lanham, Boulder.

BICKFORD, S. (1995): "In the Presence of Others: Arendt and Anzaldúa on the Paradox of Public Appearance", Feminist interpretations of Hannah Arendt, University Park, The Pennsylvania State University Press.

BIRUlÉs, F. (2007): Herencia sin testamento: Hannah Arendt, Barcelona, Herder.

BLÜCHER, H.; Arendt, H. (1996): Within four walls. The Correspondence between Hannah Arendt and Heinrich Blücher. 1936-1968, NY, Harcourt.

Campillo, A. (2002): "Espacios de aparición: el concepto de lo político en Hannah Arendt", Daimon, no 26, pp. 159-186.

Canovan, M. (1992): Hannah Arendt. A reinterpretation of her political thought, Cambridge, Cambridge University Press.

65 Sánchez Muñoz (1994), p. 128. 
Collin, F. (1992): "Hannah Arendt: la acción y lo dado", Filosofía y género. Identidades femeninas, Pamplona, editorial Pamiela, pp. 19-49.

Comesaña Santalines, G. M. (2001): "Lectura feminista de algunos textos de Hannah Arendt", Anales del Seminario de historia de la filosofía, 18, pp. $125-$ 142.

Cruz, M.; Birulés, F. (ed.) (1994): En torno a Hannah Arendt, Madrid, Centro de Estudios Constitucionales.

DelRUelle, E. (1993): Le consensus impossible. Le différend entre éthique et politique chez H. Arendt et J. Habermas, Bruxelles, Ousía.

Disch, L. J. (1995): “On Friendship in 'Dark Times"”, en Feminist interpretations of Hannah Arendt, University Park, The Pennsylvania State University Press, pp. 285-311.

Guerra Palmero, M. J. (2011): “Arendt y los feminismos: ontología y política", Daimon, Suplemento 4, pp. 203-212.

HABermas, J. (1975): "Hannah Arendt", Perfiles filosófico-políticos, Madrid, Taurus.

Honig, B. (1995): Feminist Interpretations of Hannah Arendt, University Park, The Pennsylvania State University Press.

Kristeva, J. (2001 a): Hannah Arendt, New York, Columbia University Press.

Kristeva, J. (2001): Hannah Arendt. Life is a narrative, Toronto, University of Toronto Press.

Passerin D'Entrèves, M. (1994): The Political Philosophy of Hannah Arendt, London and New York, Routlegde.

Pitkin, H. F. (1998): The attack of the Blob. Hannah Arendt's concept of the social, Chicago and London, The University of Chicago Press.

Ricoeur, P. (1991): "Pouvoir et violence", Lectures 1. Autour du politique, Paris, Seuil, pp. 20-42.

RIng, J. (1997): The Political Consequences of Thinking. Gender and Judaism in the Work of Hannah Arendt, New York, State University of New York Press.

SÁnchez Muñoz, C. (1994): "Paria o ciudadana del mundo", Cruz, M. y Birulés, F., En torno a Hannah Arendt, Centro de Estudios Constitucionales, Madrid, pp. 17-37.

SÁnchez Muñoz, C. (2003): Hannah Arendt. El espacio de la politica, Madrid, Centro de Estudios Políticos y Constitucionales.

Vicente Arregui, G. (2011): "Las mujeres y el espacio público”, La igualdad: nuevas perspectivas de género en educación, lingüística y filosofía, Biblioteca de Estudios sobre la Mujer, no 33, Málaga, pp. 225-242.

YounG-Bruehl, E. (1996): "Hannah Arendt among Feminists", May, L., Kohn, J. (eds.), Hannah Arendt. Twenty Years Later, Massachusetts, The MIT Press, pp. 307-324. 
Zerilli, L. M. G. (1995): “The Arendtian Body”, Honig, B. (ed.), Feminist interpretations of Hannah Arendt, University Park, The Pennslyvania State University Press, pp. 167-193.

Julia Urabayen

Departamento de Filosofía / ICS

Universidad de Navarra

jurabayen@unav.es 